\title{
Synthesis of Core-Shell Gold Nanoparticles with Maltose-Modified Poly(Ethyleneimine)
}

\author{
Anja Köth, ${ }^{1}$ Brigitte Tiersch, ${ }^{1}$ Dietmar Appelhans, ${ }^{2}$ Michael Gradzielski, ${ }^{3}$ \\ Helmut Cölfen, ${ }^{4}$ and Joachim Koetz ${ }^{1}$ \\ ${ }^{1}$ Universität Potsdam, Institut für Chemie, Potsdam (Golm), Germany \\ ${ }^{2}$ Leibniz-Institut für Polymerforschung Dresden e.V., Dresden, Germany \\ ${ }^{3}$ TU-Berlin, Stranski-Laboratorium, Institut für Chemie, Fakultät II, Berlin, Germany \\ ${ }^{4}$ Max-Planck-Institut für Kolloid- und Grenzfächenforschung, Abteilung Kolloidchemie, \\ Potsdam, Germany
}

\begin{abstract}
The synthesis of ultrafine gold nanoparticles in presence of maltose modified hyperbranched poly(ethyleneimines) (PEI) is described. The polymer acted as both a reducing and stabilising agent in the particle formation process. The nanoparticles were characterized by means of dynamic light scattering (DLS), transmission electron microscopy (TEM), analytical ultracentri fugation (AUC), small angle $x$ ray scattering (SAXS), and small angle neutron scattering (SANS). The mechanism of nanoparticle formation can be described in two steps. The reduction process of the $\mathrm{Au}^{3+}$ ions located in the inner coil region of the hyperbranched PEI led to the for mation of a compact gold core, and is accompanied by a collapse of the polymer coil. Therefore, in the subsequent reduction process a gold polymer hybrid shell is formed. By using the PEI of higher molar mass, core shell gold nanoparticles of about $3.6 \mathrm{~nm}$ size with a more narrow size distribution and special fluorescence behavior could be synthesized.
\end{abstract}

Keywords Gold nanoparticles, gold polymer hybrid shell, maltose modified poly (ethyleneimine)

\section{INTRODUCTION}

Gold nanoparticles have attracted considerable attention because of their unique optical, electronic and magnetic properties, ${ }^{[1-5]}$ as well as potential applications in catalysis and biology. ${ }^{[6,7]}$ The particles are used for example to enhance the sensitivity of diagnostic assays, ${ }^{[8]}$ in radiotherapy, ${ }^{[9]}$ as well as in drug delivery systems, ${ }^{[10]}$ or to improve the catalytic activity of palladium and platinum catalysts. $^{[11,12]}$

Several methods can be employed for the synthesis of gold nanoparticles from a diluted tetrachloroaureate solution. The reduction process can be carried out in different template phases, for example, using linear polymers or highly branched structures such as dendrimers, ${ }^{[13-17]}$

The authors thank Antje Völkel (MPI KGF) for the skilfully performed analytical ultracentrifugation experiments. Addition ally, they like to thank C. Oppel and S. Prévost for help with the SAXS and SANS experiments, respectively. Sibylle Rüstig is gratefully acknowledged for the TEM micrographs.

Address correspondence to Joachim Koetz, Universität Potsdam, Institut für Chemie, Karl Liebknecht Strasse 24 25, Haus 25, 14476 Potsdam (Golm), Germany. E mail: koetz@, rz.uni potsdam.de microemulsions, ${ }^{[18,19]}$ polymer gel templates, ${ }^{[20,21]}$ or mixed phospholipid vesicles. ${ }^{[22]}$ Alternatively, the reduction can occur in diluted aqueous or alcoholic solutions by adding reducing agents (e.g., sodium salt of citric acid, ${ }^{[23]}$ sodium borohydride $\mathrm{NaBH}_{4},{ }^{[24,25]}$ tannin, or urine ${ }^{[11,26]}$ ) to the aqueous solution of the $\mathrm{HAuCl}_{4}$ precursor.

The synthesis of small, monodisperse nanoparticles is still a major challenge in nanotechnology research. Taking into account the well established scientific fact that smaller particles exhibit increased driving forces to aggregate to diminish surface energy, a protective coating, or "capping," is necessary during the particle synthesis. However, it is desirable to keep the nanoparticles formed in a finely dispersed state. To prevent aggregation or coagulation phenomena in colloidal systems, the nanoparticles have to be stabilized electrostatically or sterically.

It is already demonstrated that thiolate-protected gold nanoparticles of smaller size (from $15 \mathrm{~nm}$ ) can be prepared in the presence of thiol capping ligands in different solvents. ${ }^{[26-30]}$ The disadvantage of this method is the toxicity of the organic solvent used, and restrictions of surface modification and functionalization due to the thiolate capping ligands. Another possibility is to use a polymer as an effective protective agent for synthesising size and shape 
controlled gold nanoparticles. ${ }^{[31]}$ Therefore, different types of polymers can be applied, including DNA, ${ }^{[32,33]}$ thermo-responsive polymers (e.g., PNIPAM ${ }^{[34]}$ ), or amphiphilic block copolymers. ${ }^{[35]}$ Most commonly used polymers are poly(vinylpyrrolidone), poly(ethylene glycol) and their block copolymers. ${ }^{[36-38]}$ Polyelectrolytes, which are water soluble macromolecules with a lot of dissociating functional groups, are of special interest for stabilising nanoparticles due to the fact that they combine the steric stabilising effect with the electrostatic one. Thus, their use results in an electrosterically stabilized colloidal system. ${ }^{[39]}$

Furthermore, it was shown that polyanions (e.g., polyacrylates $^{[40]}$ ), polyampholytes (e.g., maleic acid copolymers $^{[41]}$, as well as polycations ${ }^{[42]}$ can be successfully used. Different research groups have already shown that for example linear and branched poly(ethyleneimines) (PEI) can reduce a gold chloride solution and stabilize the gold nanoparticles formed. ${ }^{[18,43-48]}$ Sun et al. ${ }^{[49]}$ have prepared very stable, but polydisperse PEI-stabilized gold nanoparticles.

Recently, we have demonstrated that oligosaccharidemodified poly(ethyleneimines) can be successfully used in the gold nanoparticle formation process, too. ${ }^{[49]}$ Gold nanoparticles with particle diameters between 2 and $20 \mathrm{~nm}$ were obtained. The size and shape of the polymer-stabilized nanoparticles can be tuned by changing the solute concentration, the time of heating, as well as the $\mathrm{pH}$ value. Besides, differences in the reducing and stabilising properties of the PEI samples were found in dependence on the degree of substitution with oligosaccharides. Therefore, we were able to show that the reducing power is related predominantly to the secondary amino groups according to a reduction mechanism already proposed by Wang et al. ${ }^{[50]}$

However, the mechanism of particle formation is not well understood. Also, the synthesis of monodisperse, biocompatible gold nanoparticles by this way is still a challenge. Furthermore, it is still an open question, why the hydrodynamic radius of the polymer-stabilized gold nanoparticles measured by dynamic light scattering was quite equal to the radius of the gold particles obtained by transmission electron microscopy. ${ }^{[49]}$

Therefore, our research is directed towards the better understanding of the formation mechanism of ultrafine gold particles $(\leq 5 \mathrm{~nm}$ in size) in the presence of oligosaccharide-modified hyperbranched PEI. Especially, the stabilization of such gold nanoparticles is mainly assumed to take place by an interfacial uptake process at which the gold nanoparticles are preferentially wrapped by several PEI macromolecules. This simplified explanation will hide from other potential stabilization processes. One possible stabilization process can be an isolated gold nanoparticle in the dendritic scaffold of the oligosaccharide-modified hyperbranched PEI. This imaginable stabilization of very small gold nanoparticles is also tailored by the structural features of the oligosaccharidemodified hyperbranched PEI to act simultaneously as reducing and stabilising agent.

For the present work we synthesized two maltosemodified hyperbranched PEI samples I and II. The only difference of both samples (I and II) is their molar mass. For a more comprehensive characterization of the gold nanoparticles with regard to growth and stabilization processes, we compared DLS with SAXS and SANS measurements and used the ultracentrifugation technique in combination to high resolution transmission electron microscopy (HRTEM). The aim of the study was to establish the next generation of biocompatible sugar-modified gold nanoparticles with special fluorescence features.

\section{EXPERIMENTAL}

\subsection{Materials}

The hyperbranched poly(ethyleneimine) samples I II (Figure 1) were synthesized via a reductive amination of the hyperbranched PEI, with $\mathrm{M}_{\mathrm{w}}$ of 5,000 and $25,000 \mathrm{~g} /$ mol. The molar ratio of PEI and maltose was 1:0.5. Further details of the synthesis and characterization of the maltose-modified PEI have been published. ${ }^{[51]}$ The metal precursor hydrogen tetrachloroaureate $\mathrm{HAuCl}_{4}$ was purchased from Aldrich. Water was purified with the Modulab PureOne water purification system (Continental).

\subsection{Colloidal Gold Preparation}

Aqueous solutions of the two maltose-modified PEI samples I and II (1\% by weight) were prepared and stirred

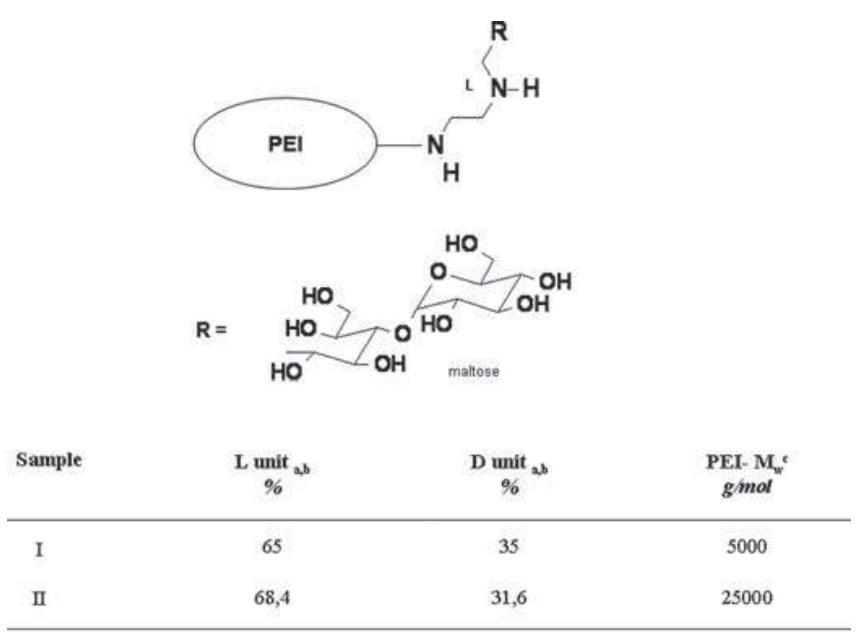

- L- linear, D- dendritic, determined by elemental analysis

As one example for unmodified PEI with $5000 \mathrm{~g} / \mathrm{mol} 32 \% \mathrm{~T}$ units, $36.7 \% \mathrm{~L}$ units and $30.7 \% \mathrm{D}$. units. Unmodified PEI with M, 5000 or $25000 \mathrm{~g} / \mathrm{mol}$ was converted with maltose.

FIG. 1. Structure of the maltose modified poly(ethyleneimine). 
24 hours before use. The aqueous tetrachloroaureate precursor solution $(2 \mathrm{mM})$ was freshly prepared. Each polyelectrolyte solution was mixed with the metal precursor solution in a weight ratio of polyelectrolyte to metal $=1: 1$ at room temperature.

\subsection{Methods}

\subsubsection{Dynamic Light Scattering}

Dynamic light scattering measurements were carried out at $25^{\circ} \mathrm{C}$ at a fixed angle of $173^{\circ}$ by using a Nano Zetasizer 3600 (Malvern), equipped with a He-Ne laser $(4 \mathrm{~mW})$ and a digital autocorrelator. It has to be mentioned here that this $173^{\circ}$ backscattering technique is a useful method to detect particles of very small dimensions down to $1 \mathrm{~nm}$. Recently published data show that subnanometer measurements are achievable with a precision of $0.1 \mathrm{~nm} .{ }^{[52]}$ The particle size distribution was determined by using a multimodal peak analysis by intensity, volume, and number. The mean particle size is the average value of 10 measurements by using the multimodal peak analysis by number.

\subsection{2. $U V$-Vis Spectroscopy}

UV-vis experiments were performed with a LS 5 (Perkin Elmer) UV-vis NIR spectrometer in the wavelength range between 200 and $800 \mathrm{~nm}$ using quartz cuvettes with a path length of $1 \mathrm{~cm}$.

\subsubsection{Luminescence Spectroscopy}

A Fluoromax-3 spectrofluorometer (Horiba Jobin Yvon) was used to measure the fluorescence. The spectra were recorded in a wavelength range between 530 and $750 \mathrm{~nm}$ at the excitation wavelength of $510 \mathrm{~nm}$.

\subsubsection{Transmission Electron Microscopy}

Samples were prepared by dropping the colloidal dispersion on the copper grids. After air drying the samples were examined in the transmission electron microscope EM 902 (Zeiss) at an acceleration voltage of $90 \mathrm{kV}$. For a more comprehensive characterization high resolution transmission electron microscope (HRTEM) images of the particles were conducted in a LIBRA 200FE-HT (Zeiss), and a JEM-2200 FS (JEOL), respectively.

\subsubsection{Analytical Ultracentrifugation}

Analytical ultracentrifugation (AUC) is a fractionating technique for determination of the particle size distribution. ${ }^{[53,54]}$ It is an absolute method demanding no standards and can detect particles with sizes less than $1 \mathrm{~nm}$ up to $5000 \mathrm{~nm}$. An important parameter for the evaluation is the knowledge of the particle density which can be problematic for charged, small, and hybrid nanoparticles. Analytical ultracentrifugation was performed on an Optima
XL-I (Beckman Coulter) using the UV-vis absorption optics at $25^{\circ} \mathrm{C}$.

\subsubsection{Small Angle X-Ray Scattering (SAXS)}

Mean size and size distribution of gold nanoparticles can be determined by small angle x-ray scattering (SAXS).

SAXS measurements were carried out in $\mathrm{D}_{2} \mathrm{O}$, using the ID02 instrument at the ESRF, Grenoble (France). A wavelength of $0.995 \AA$ and a sample-to-detector distance of $1.0862 \mathrm{~m}$ were used. The exposure time amounted to $100 \mathrm{~ms}$.

\subsubsection{Small Angle Neutron Scattering (SANS)}

For obtaining more detailed information about the core-shell structure of the particles, small-angle neutron scattering (SANS) measurements were carried out in $\mathrm{D}_{2} \mathrm{O}$ as solvent in order to have a better contrast. The SANS experiments were carried out at the Laboratoire Léon Brillouin (LLB), Saclay (France), using the PAXY instrument installed on the neutron guide G2 (cold source) of the Orphee reactor. A wavelength of $5 \AA$ and sample-todetector distances of 1.2 and $5 \mathrm{~m}$ were employed thereby covering a q-range of 0.009 to $0.38 \AA{ }^{1}$. The raw data recorded on a $128 * 128$ 2-dimensional detector were azimuthally averaged, corrected for the background due to cell scattering and detector noise, and then, by taking into account the transmission of the samples, converted into absolute units by calibration with the intensity of the direct beam. ${ }^{[5]}$ The solvent scattering was not subtracted therefore the scattering data still contain the incoherent background of the solvent. All SANS measurements were performed at $25 \pm 0.2^{\circ} \mathrm{C}$.

\section{RESULTS AND DISCUSSION}

After mixing the maltose-modified PEI solution ( $1 \mathrm{wt} \%)$ with the $2 \mathrm{mM} \mathrm{HAuCl}_{4}$ solution in a mass ratio of $1: 1$, the mixture was stirred for 5 days at room temperature. Thus, a brown colored solution was observed.

\subsection{UV-Vis Measurements}

Red colored, colloidal gold sols with particle sizes of about $20 \mathrm{~nm}$, produced by the well-known route of Turkevich (already published more than 50 years ago ${ }^{[23]}$ ), show an absorption maximum at about $520 \mathrm{~nm}$. Note, the distinct value of the absorption maximum of colloidal gold sols strongly depends on the particle size, the type of stabilizer, and the step of aggregation. ${ }^{[18,26,39]}$ Subnanometer-sized gold clusters show an absorption in the $400420 \mathrm{~nm}$ range. For example brown colored $\mathrm{Au}_{11}$ clusters with diameter of about $0.8 \mathrm{~nm}$ exhibit an absorption maximum at $415 \mathrm{~nm}$, which can be assigned to the $5 \mathrm{~d} \rightarrow 6 \mathrm{~s}$ interband transitions in the cluster core. ${ }^{[56]}$ 


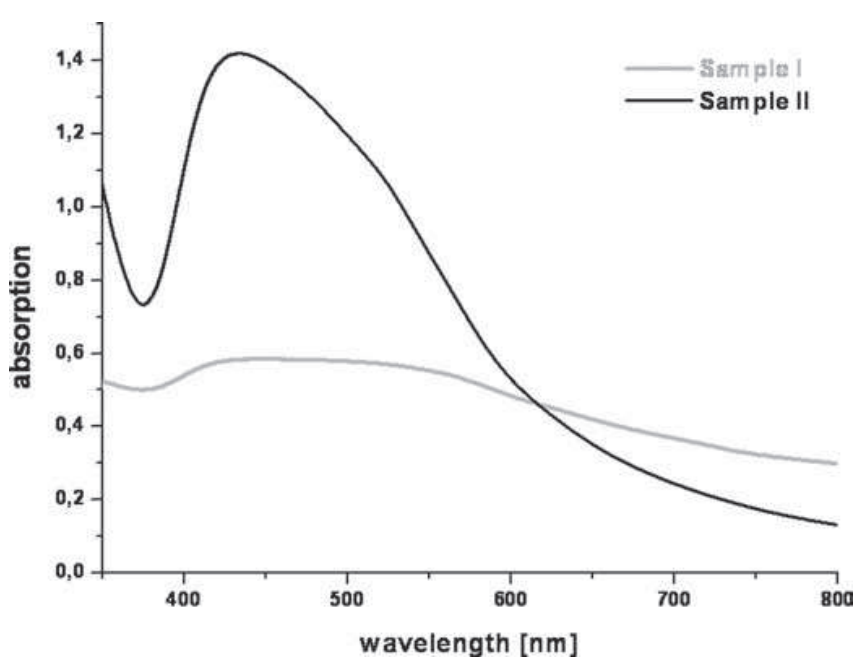

FIG. 2. UV vis spectra of gold nanoparticles produced with sample I and sample II at room temperature.

The UV-vis spectrum of our brown colored solution I (Figure 2a) shows a plateau between 425 and $550 \mathrm{~nm}$. Thus, a broad particle size distribution can be assigned from very small gold clusters ( $<3 \mathrm{~nm}$ in size) up to "larger" gold nanoparticles in the size range of about $10 \mathrm{~nm}$.

The distinguishing feature between the UV-vis spectrum of the gold nanoparticles synthesized with sample II (Figure 2b) and the spectrum with sample I (Figure 2a) is that the absorption shoulder at $520 \mathrm{~nm}$ is not so pronounced and only a clear absorption maximum at $435 \mathrm{~nm}$ can be observed. That indicates the formation of significantly smaller gold nanoparticles.

Therefore, the following investigations were performed with the higher molecular weight sample II.

\subsection{DLS Measurements}

Dynamic light scattering is a useful method to determine the particle size and particle size distribution of polymer coils as well as nanoparticles.

The hydrodynamic diameter of the aqueous solution of PEI sample II (in absence of a gold chloride solution) is $6.9 \pm 2.7 \mathrm{~nm}$. When the polymer solution is mixed with the $\mathrm{HAuCl}_{4}$ solution, accompanied by the direct visible color effect, the DLS particle size distribution shows two particle fractions at 3.6 and $15.3 \mathrm{~nm}$ in the intensity plot. It has to be mentioned that the fraction at $15.3 \mathrm{~nm}$ disappears in the number plot (Figure 3). Therefore, one can conclude that the main fraction is the gold nanoparticle fraction with mean diameter of $3.6 \pm 1.2 \mathrm{~nm}$, and the other one is only an aggregate fraction of minor concentration.

The disappearance of the polymer peak at $6.9 \mathrm{~nm}$ after mixing with the gold precursor solution can be explained by a compactization of the polymer coil during the

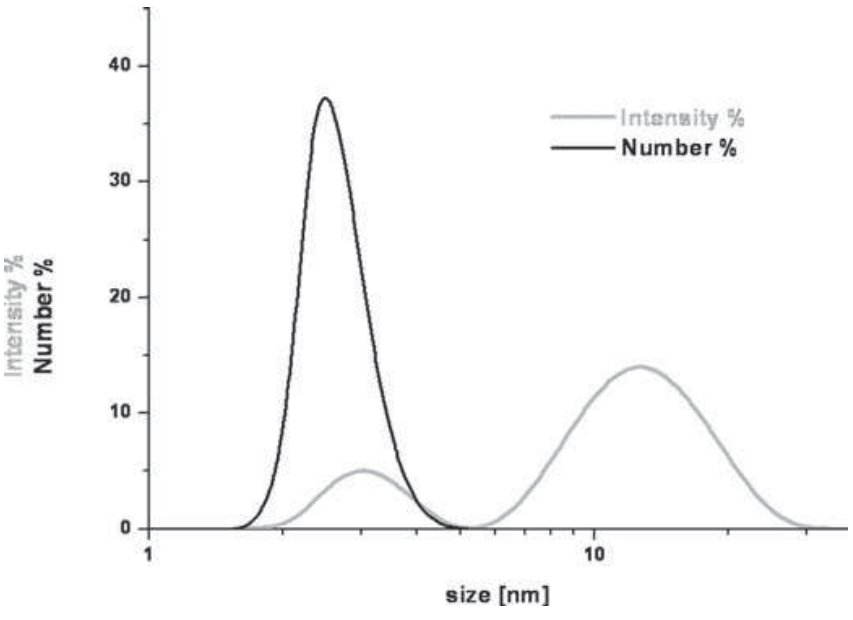

FIG. 3. Intensity and number plot of DLS of the gold nanoparticle solution.

nanoparticle formation process. To facilitate the assumption time dependent DLS measurements were performed. After mixing the polymer solution with the metal precursor solution the polymer coil dimension decrease to $4.6 \pm 1.3 \mathrm{~nm}$ (Figure 4). Thus, the compactization of the polymer coil is caused by the formation of the nanoparticles.

\subsection{AUC Measurements}

The analytical ultracentrifugation (AUC) is a well established method to determine the size and shape of colloidal particles. The particle size and particle size distribution can be obtained by measuring the sedimentation velocity.

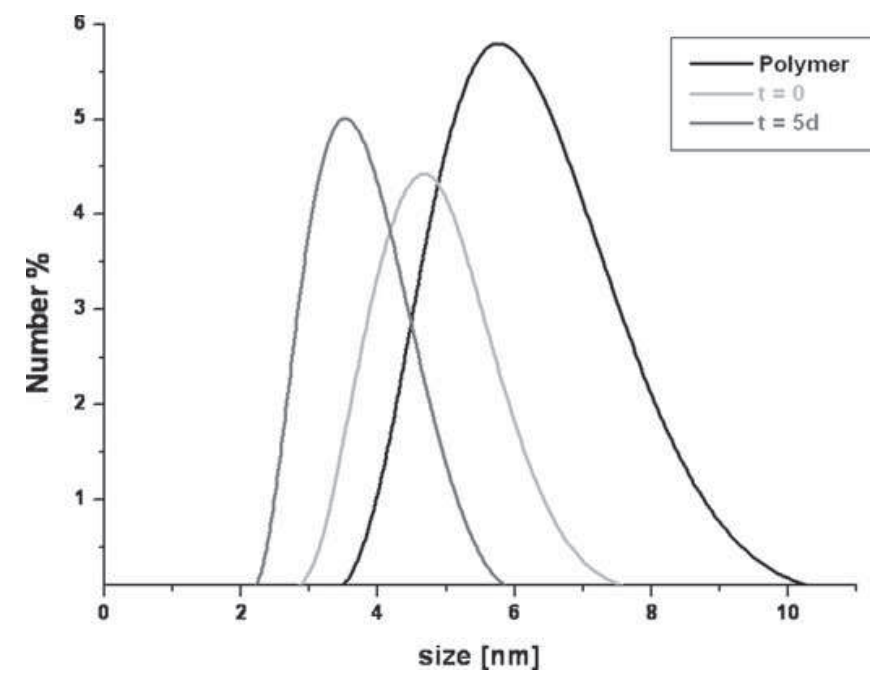

FIG. 4. Time dependent DLS measurements during the gold nano particle formation. 


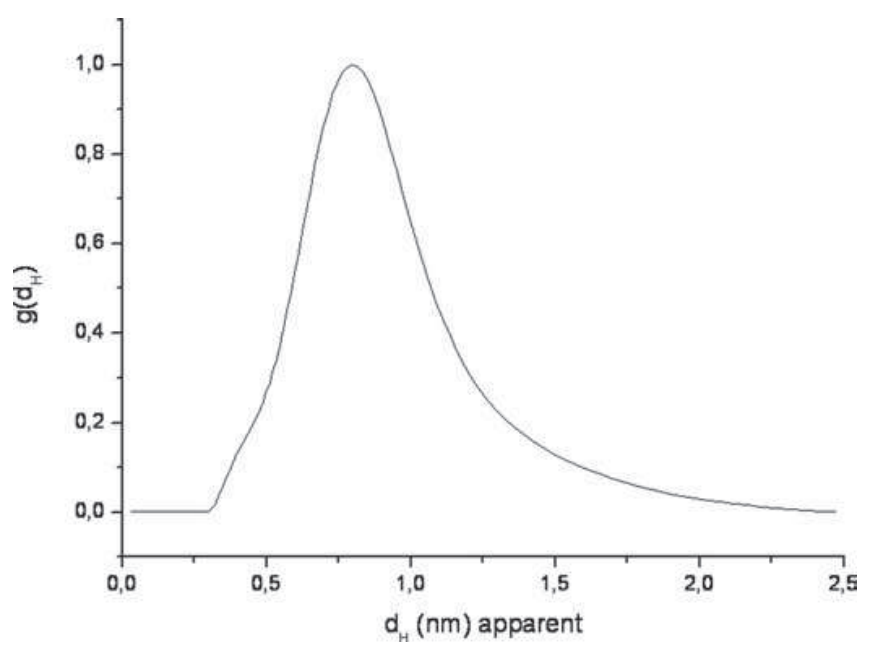

FIG. 5. AUC spectrum of the gold nanoparticle solution.

In the last decade, the application of AUC to nanomaterial analysis has been expanded substantially. Here, different nanoparticles, for example, $\mathrm{TiO}_{2}, \mathrm{Fe}_{3} \mathrm{O}_{4}, \mathrm{ZrSO}_{4}$, $\mathrm{FePt}, \mathrm{ZnO}$, and $\mathrm{Pt}$ were characterized ${ }^{[57-59]}$ and resolution of the particle size distribution in the Angström range was reported. ${ }^{[60]}$ One of the first systems investigated by ultracentrifugation was an aqueous gold dispersion almost a hundred years ago. ${ }^{[61]}$

The average size of the gold nanoparticles calculated from the sedimentation coefficient on basis of the bulk gold density is $0.8 \mathrm{~nm}$ (Figure 5). That means the particle size obtained by means of AUC measurements is significantly smaller than the diameter measured with DLS. Taking this discrepancy into account the particle density has to be checked in more detail, because of the fact that the particle density is the most important parameter for the particle size calculation in the AUC. Note, that the density of $\mathrm{Au}$ $\left(19.32 \mathrm{~g} / \mathrm{cm}^{3}\right)$ is much higher than the density of the maltose-modified PEI $\left(1.00082 \mathrm{~g} / \mathrm{cm}^{3}\right)$. That means by calculating with the density of the pure polymer shell unreal large particle dimensions will be obtained. Taken into account the particle dimensions obtained by DLS one can conclude that an Au-polymer hybrid shell should be formed.

\subsection{SAXS Measurements}

Furthermore, the size and size distribution can be investigated by using the technique of small angle X-ray scattering (SAXS). ${ }^{[62-64]}$ From the slope in the Guinier plot, a mean radius can be calculated according to Equation (1). ${ }^{[65]}$

$$
\ln \left(\frac{I(q)}{I(0)}\right)=-R^{2} * q^{2} 5
$$

SAXS pattern of our sample shows an obvious shoulder at around $0.15 \AA^{1}$ (Figure 6). This graph behavior is

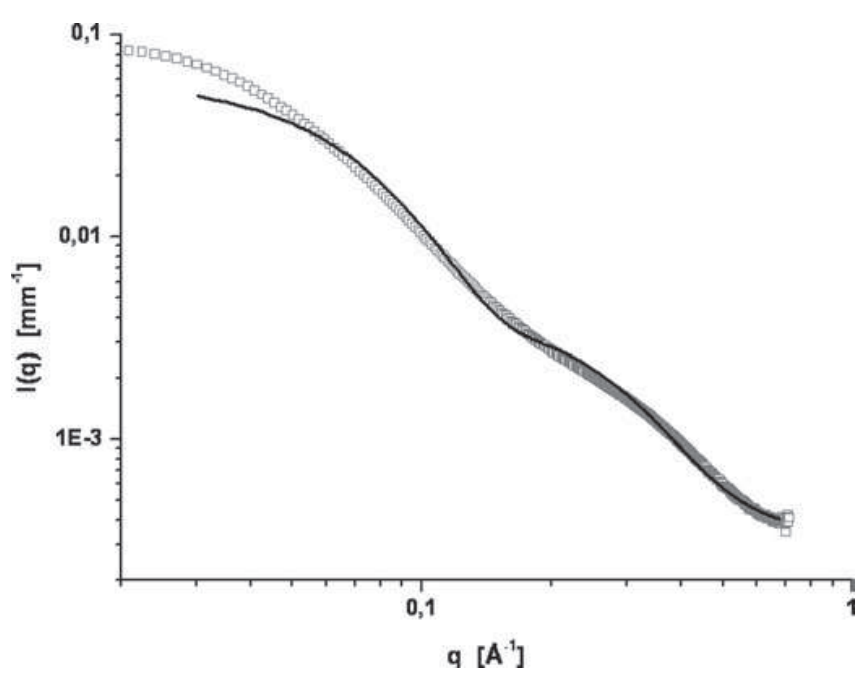

FIG. 6. SAXS pattern of the gold nanoparticle solution with a polydisperse core shell fit. Data were taken at $25^{\circ} \mathrm{C}$.

characteristic for core-shell systems. Above $0.15 \AA^{1}$ the scattering is dedicated primarily to the core, whereas below $0.15 \AA^{1}$ the scattering is related to the shell.

The Guinier plot of the SAXS measurement shows two linear areas, from those the calculation of the core radius and shell thickness is possible (Figure 7). The Au core diameter calculated from a core-shell model is $1.5 \mathrm{~nm}$ and the shell exhibit a thickness of $3.3 \mathrm{~nm}$. Finally the polymer entrapped nanoparticles are $6.7 \mathrm{~nm}$ in size, which is higher than the diameter obtained by DLS, TEM, and AUC. Taking into account that we have used the scattering length density of poly(ethyleneimine) for the shell calculation, we

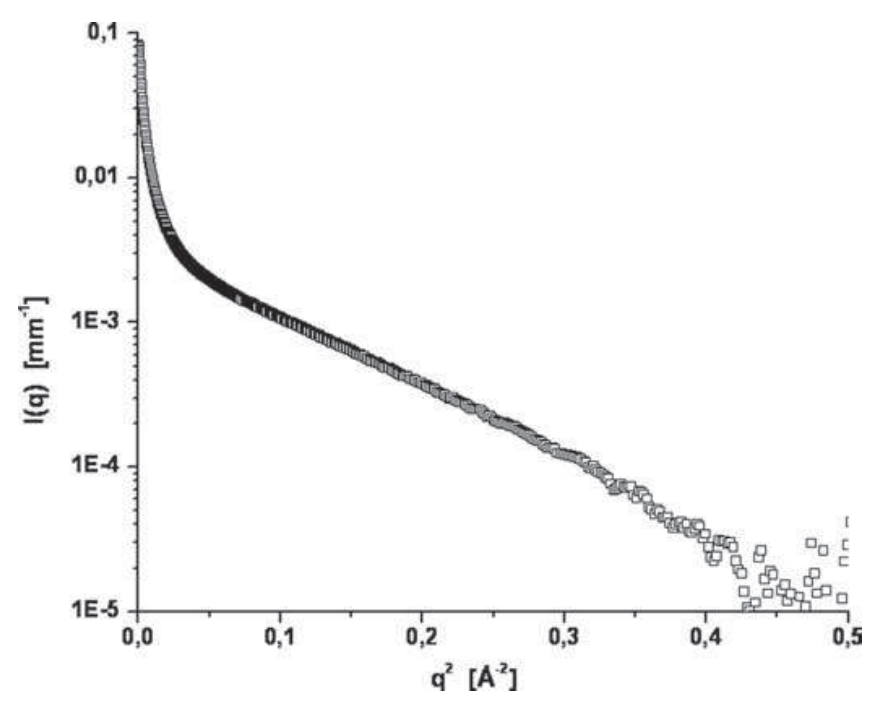

FIG. 7. Guinier plot of the SAXS pattern of the gold nanoparticle solution. 


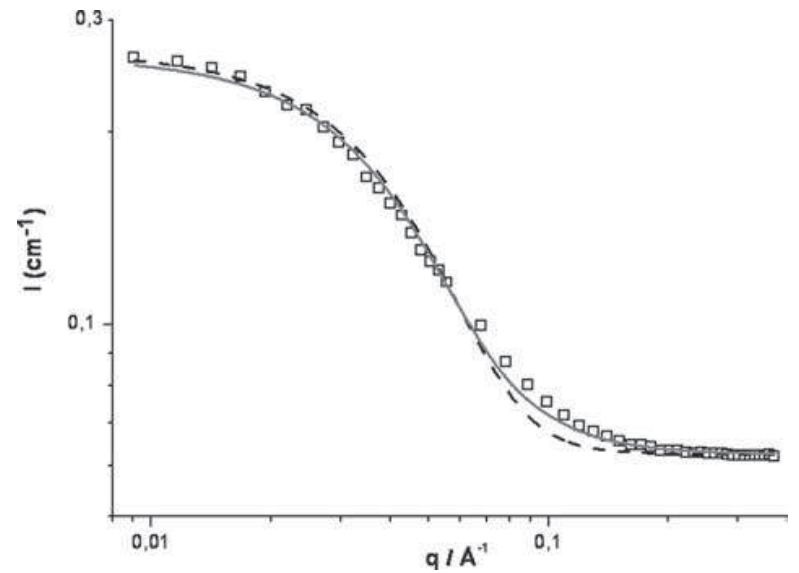

FIG. 8. Small angle neutron scattering intensity (at $25^{\circ} \mathrm{C}$ ) as a func tion of the magnitude of the scattering vector for the gold nanoparticle sol ution II. Fits with models of a polydisperse (Schulz distribution) homogeneous sphere (black broken line) and with a polydisperse (Schulz distribution) core shell model (grey continuous line) are included

conclude, that the synthesized gold nanoparticles consist of a gold-polymer hybrid shell (with a different scattering length density as the pure polyelectrolyte) instead of an unmodified polymer shell.

\subsection{SANS Measurements}

Small-angle neutron scattering provides information on the microstructure through measuring angular dependence of neutron intensity. It is a very useful technique to investigate for example micelles and interpolyelectrolyte complexes (IPEC) having a core-shell structure ${ }^{[66,67]}$ similar to the one expected for our polymer covered Au nanoparticles. SANS measurements were performed on gold nanoparticle solution in $\mathrm{D}_{2} \mathrm{O}$. The intensity curve was fitted with a model of a polydisperse homogeneous sphere (black line in Figure 8).

The diameter obtained from this polydisperse homogeneous sphere model is $6.0 \mathrm{~nm}$. The fit shows a good agreement for the low q-range but significant deviations for the q-range about $0.1 \AA^{1}$ (black broken line in Figure 8).

In order to account for these deviations, we employed a polydisperse core-shell model with an Au-core and a polymer shell. By using this fit a much better agreement with the experimental data can be obtained for particles with a gold-core diameter of $1.1 \mathrm{~nm}$ and a shell thickness of $1.5 \mathrm{~nm}$ (grey continuous line in Figure 8), where the shell accounts for the polymer covering the gold nanoparticles.

\subsection{TEM Images}

The TEM micrograph of the gold nanoparticle solution shows the existence of spherical, small nanoparticles. The diagram of 500 particles (Figure 9) shows a more narrow
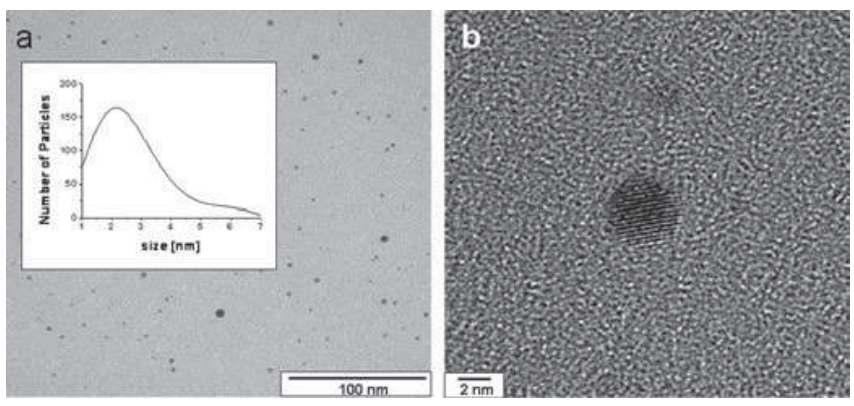

FIG. 9. TEM (a) and HRTEM (b) micrographs of the gold nano particle solution.

size distribution with a mean particle size of $3.1 \pm 1.2 \mathrm{~nm}$. The nanoparticles were also analyzed by means of HRTEM to analyze the crystallographic structure.

It is well known that the gold nanoparticles in the order of few nanometers show different morphologies including octahedral, icosahedral, or pentagonal decahedral shapes and their twinned variants. ${ }^{[68]}$ Many researchers have used the high resolution electron microscopy which provides direct atomistic information on individual particles.

Figure $9 \mathrm{~b}$ shows a typical HRTEM image of a spherical gold nanoparticle $3 \mathrm{~nm}$ in size. The experimental HRTEM images show a typical pattern, where the fringes are separated by $2.09 \AA$. Note that this distance is included in the list of allowed distances in the gold unit cell, and corresponds to the (200) planes distances for a gold face centered cubic (fcc) unit cell. However, for a more detailed consideration HRTEM images have to be compared with multislice simulations for different morphologies, i.e., icosahedron (ih), decahedron (dh), and fcc polyhedrons. ${ }^{[68]}$ Koga et al. have shown for example that simulation images of dh particles show similar TEM images in dependence on the tilting angle. ${ }^{[69]}$ Note that the analysis of the contrast in icosahedral gold nanoparticles can be quite similar to the one observed in a quasicrystalline structure. ${ }^{[70]}$

\subsection{PL Measurements}

The photoluminescence phenomenon was first reported in 1998 by Wilcoxon et al., observing a blue emission at $440 \mathrm{~nm}$ from gold quantum dots with diameter smaller than $2.5 \mathrm{~nm} .{ }^{[71]}$ Whetten and Murray separately detected a near-infrared to visible fluorescence by using gold nanoparticles smaller than $1.8 \mathrm{~nm} .{ }^{[72-74]}$ The near-infrared luminescence was led back to the HOMO-LUMO electron transition, whereas the visible emission was ascribed to the interband transition between the filled $5 \mathrm{~d}^{10}$ band and the $6 \mathrm{sp}^{1}$ conduction band. ${ }^{[71-73]}$ Figure 10 shows the emission spectrum of the gold nanoparticle solution excited at $510 \mathrm{~nm}$. The two emission peaks at 560 and $618 \mathrm{~nm}$ demonstrate the fluorescence properties of the PEI entrapped nanoparticles. The rather substantial difference between 


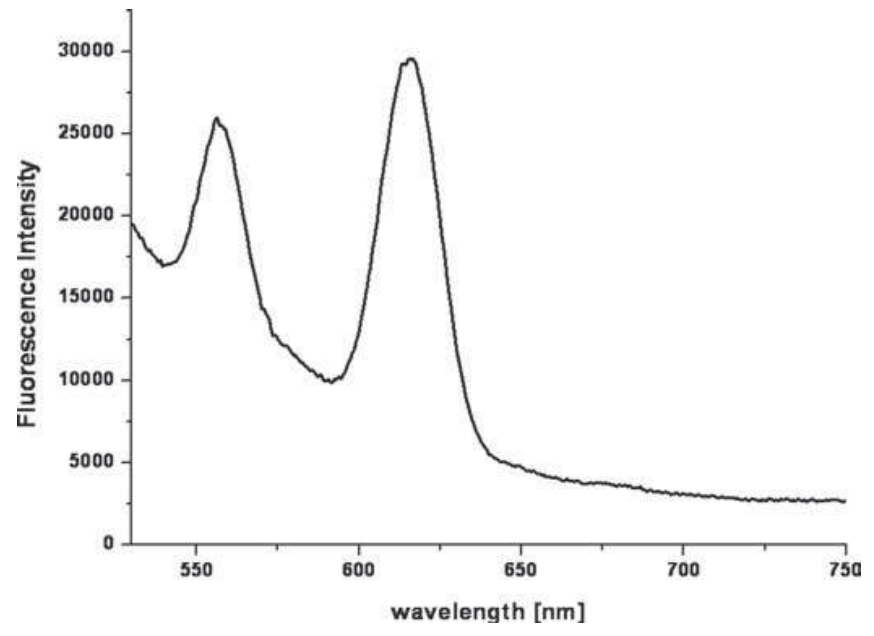

FIG. 10. Fluorescence spectrum of gold nanoparticle solution excited at $510 \mathrm{~nm}$.

the excitation and emission peak indicates that the particles behave as indirect band-gap semiconductor materials.

The luminescence of gold nanoparticles smaller than $5 \mathrm{~nm}$ is dependent on the surface protecting ligands, too. Yang et al. ${ }^{[75]}$ found that no luminescence was observed with $\mathrm{Au}_{11} \mathrm{Cl}_{3}\left(\mathrm{PPh}_{3}\right)_{7}$ gold nanoparticles which consist of a gold core around $0.8 \mathrm{~nm}$, whereas the gold nanoparticles after ligand exchange with n-dodecanethiol show an emission peak at $842 \mathrm{~nm}$.

Taking into account that the "pure" aqueous polymer solution shows an emisson peak at $625 \mathrm{~nm}$, one can conclude that the second peak at $618 \mathrm{~nm}$ of the gold nanoparticle solution can be assigned to dissolve polymer chains, whereas the peak at $560 \mathrm{~nm}$ is related to the polymer entrapped nanoparticles.

\section{CONCLUSIONS}

First, our results show that maltose-modified poly(ethyleneimines) can be successfully used for the synthesis of gold nanoparticles only by mixing the gold chloride precursor solution with the polymer solution at room temperature.

By using the PEI sample I of low molar mass a broad particle size distribution is obtained, where nanoparticles between 2 and $10 \mathrm{~nm}$ are formed.

By increasing the molar mass of the polymer gold nanoparticles with a more narrow particle size distribution can be produced. From AUC, SAXS, and SANS measurements one can conclude that the particles have a compact gold core of about $1 \mathrm{~nm}$. In addition our SAXS and SANS measurements indicate that the gold core is surrounded by a polymer shell. Taking into account the particle dimensions obtained by DLS (of about $3.6 \mathrm{~nm}$ ) and TEM (of about $3.1 \mathrm{~nm}$ ) one can conclude that the Au core is surrounded instead of a

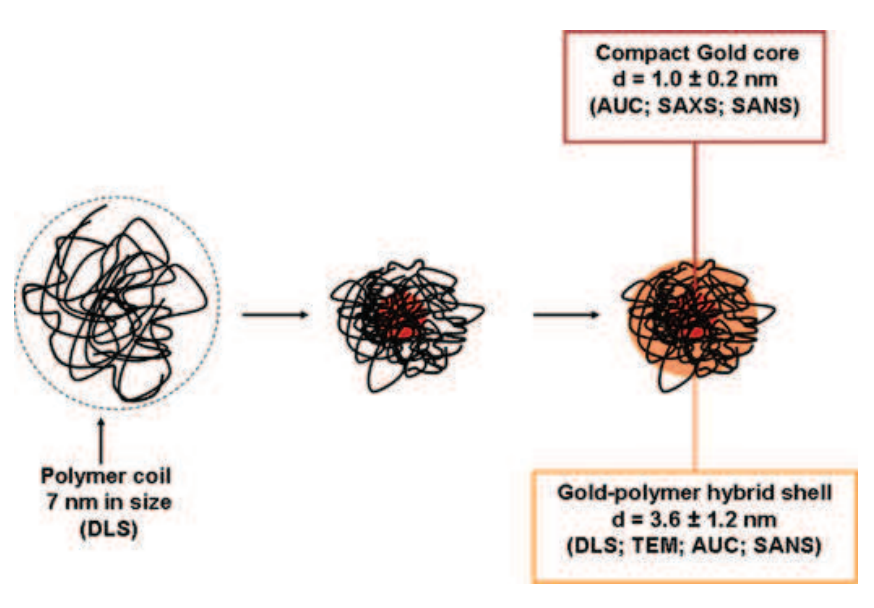

SCH. 1. Gold nanoparticle formation process in presence of the hyperbranched PEI. (Figure available in color online.)

pure polymer shell by a Au-polymer hybrid shell as already indicated by our AUC measurements. These results clearly show that only a combination of different methods, that is, DLS, TEM, SAXS, SANS, and AUC opens a way for a more comprehensive characterization of the structure of the gold nanoparticles.

Summarising the results obtained here, the mechanism of the gold reduction process in presence of the hyperbranched PEI can be described as follows (compare Scheme 1):

- In the first step, the $\mathrm{Au}^{3+}$ ions are reduced to elemental $\mathrm{Au}^{0}$ at the secondary amino groups of the polymer coil, located in the inner coil region of the hyperbranched sugar-modified PEI molecule. The Au-crystallization process induces a collapse of the polymer coil and a compact gold core of about $1 \mathrm{~nm}$ in size is formed.

- The subsequent reduction process in the collapsed polymer coil leads to the formation of a gold-polymer hybrid shell. The finally obtained gold nanoparticles are core-shell nanoparticles with an inner compact Au-core and a gold-polymer hybrid shell.

\section{REFERENCES}

[1] Demaille, C., Brust, M., Tsionsky, M., and Bard, A.J. (1997) Anal. Chem., 69: 23232328.

[2] Hayward, R.C., Saville, D.A., and Aksay, I.A. (2000) Nature, 404: 5659.

[3] Braun, E., Eichen, Y., Sivan, U., and Ben Yoseph, G. (1998) Nature, 391: 775778.

[4] Chen, M., Yamamuro, S., Farrell, D., and Majetich, S.A. (2003) J. Appl. Phys., 93: 75517553.

[5] Ciebien, J.F., Cohen, R.E., and Duran, A. (1998) Supramol. Sci., 5: 3139. 
[6] Haruta, M., Yamada, N., Kobayashi, T., and Iijima, S. (1989) J. Catal., 115: 301389.

[7] Valden, M., Lai, X., and Goodman, D.W. (1998) Science, 281: 16471650.

[8] Goodman, C.M., McCusker, C.D., Yilmaz, T., and Rotello, V.M. (2004) Bioconjugate Chem, 15: 897900.

[9] Hainfeld, J.F., Slatkin, D.N., and Smilowitz, H.M. (2004) Phys. Med. Biol., 49: N309 N315.

[10] Thomas, M. and Klibanov, A.M. (2003) PNAS, 100: 91389143.

[11] Hayat, M.A. (1989) Colloidal Gold: Principles, Methods, and Applications; New York: Academic.

[12] Hyatt, A.D. and Eaton, B.T. (1993) Immuno Gold Electron Microscopy in Virus Diagnosis and Research; Boca Raton, FL: CRC Press.

[13] Pietsch, T., Appelhans, D., and Gindy, N. (2009) Colloids Surf. A, 341: 93102.

[14] Faul, C.F. J., Antonietti, M., Hentze, H.P., and Smarsly, B. (2003) Colloids Surf., 212: 115121.

[15] Grohn, F., Kim, G., Bauer, A.J., and Amis, E.J. (2001) Macromolecules, 34: 21792185.

[16] Yu, S.H., Cölfen, H., and Mastai, Y. (2004) J. Nanosci. Nanotechnol., 4: 291298.

[17] Bronstein, L.M., Sidorov, S.N., and Gourkova, A.Y. (1998) Inorg. Chim. Acta, 280: 348354.

[18] Note, C., Kosmella, S., and Koetz, J. (2006) Colloids Surf. A, 290: 150156.

[19] Capek, I. (2004) Adv. Colloid Interface Sci., 110: 4974.

[20] Caruso, R.A., Giersig, M., Willig, F., and Antonietti, M. (1998) Langmuir, 14: 63336336.

[21] Caruso, R.A., Antonietti, M., Giersig, M., Hentze, H.P., and Jia, J. (2001) Chem. Mater., 13: 11141123.

[22] Robertson, D., Tiersch, B., Kosmella, S., and Koetz, J. (2007) J. Colloid Interface Sci., 305: 345351.

[23] Turkevich, J., Stevenson, P.C., and Hiller, J. (1951) Discuss. Faraday Soc., 11: 5575.

[24] Chen, S. and Kimura, K. (1999) Langmuir, 15: 10751082.

[25] Kuo, C.H. and Huang, M.H. (2005) Langmuir, 21: 20122021.

[26] Katz, E. and Willner, I. (2004) Angew. Chem., 116: 61666235.

[27] Brust, M., Walker, M., Bethell, D., Schiffrin, D.J., and Whyman, R. (1994) J. Chem. Soc., Chem. Commun., 801802.

[28] Donkers, R.L., Lee, D., and Murray, R.W. (2004) Langmuir, 20: 19451952.

[29] Woehrle, G.H., Warner, M.G., and Hutchison, J.E. (2002) J. Phys. Chem. B, 106: 99799981.

[30] Yang, Y. and Chen, S. (2003) Nano Lett., 3: 7579.

[31] Shan, J. and Tenhu, H. (2007) Chem. Commun., 45804598.

[32] Mirkin, C.A., Letsinger, R.L., Mucic, R.C., and Storhoff, J.J. (1996) Nature, 382: 607609.

[33] Witten, K.G., Bretschneider, J.C., Eckert, T., Richtering, W., and Simon, U. (2008) Phys. Chem. Chem. Phys., 10: 18701875 .

[34] Shan, J., Nuopponen, M., Jiang, H., Kauppinen, E., and Tenhu, H. (2003) Macromolecules, 36: 45264533.

[35] Mayer, A.B.R. and Mark, L.E. (2000) Polymer, 41: 16271631.
[36] Mayer, A.B.R. and Mark, J.E. (1998) Eur. Polym. J., 34: 103108.

[37] Kim, F., Connor, S., Song, H., Kuykendall, T., and Yang, P. (2004) Angew. Chem. Int. Ed., 43: 36733677.

[38] Filali, M., Meier, M.A.R., Schubert, U.S., and Gohy, J.F. (2005) Langmuir, 21: 79958000.

[39] Koetz, J. and Kosmella, S. (2007) Polyelectrolytes and Nanoparticles; Berlin: Springer.

[40] Note, C., Koetz, J., Kosmella, S., and Tiersch, B. (2005) Colloid Polym. Sci., 283: 13341342.

[41] Note, C., Koetz, J., Wattebled, L., and Laschewsky, A. (2007) J. Colloid Interface Sci., 308: 162169.

[42] Mayer, A.B.R. and Mark, J.E. (1997) J. Macromol. Sci. A, 34: 21512164.

[43] Chen, C.C., Hsu, C.H., and Kuo, P.L. (2007) Langmuir, 23: 68016806.

[44] Sharma, G. and Ballauff, M. (2004) Macromol. Rapid Commun., 25: 547552.

[45] Sun, X., Dong, S., and Wang, E. (2005) J. Colloid Interface Sci., 288: 301303.

[46] Sun, X., Dong, S., and Wang, E. (2004) Polymer, 45: 21812184

[47] Sun, X., Zhang, Z.L., and Wang, E. (2003) Chin. Chem. Lett., 14: 866869.

[48] Esumi, K., Hosoya, T., Suzuki, A., and Torigoe, K. (2000) Langmuir, 16: 29782980.

[49] Köth, A., Koetz, J., Appelhans, D., and Voit, B. (2008) Colloid Polym. Sci., 286: 13171327.

[50] Wang, S.T., Yan, J.C., and Chen, L. (2005) Mater. Lett., 59: 13831386

[51] Appelhans, D., Komber, H., Quadir, M.A., Richter, S., Schwarz, S., van der Vlist, J., Aigner, A., Müller, M., Loos, K., Seidel, J., Arndt, K.F., Haag, R., and Voit, B. (2009) Biomacromolecules, 10: 11141124.

[52] Kaszuba, M., McKnight, D., Connah, M.T., McNeil Watson, F.K., and Nobbmann, U. (2008) J. Nanopart. Res., 10: 823829.

[53] Cölfen, H. (2004) ACS Symp. Ser., 881: 119137.

[54] Cölfen, H. (2004) Encyclopedia of Nanoscience and Nanotech nology, 1: 6787.

[55] Cotton, J.P. (1991) In Neutron, X ray and Light Scattering, edited by P. Lindner and T.H. Zemb; Amsterdam, the Netherlands: North Holland; p. 19.

[56] Bertino, M.F., Sun, Z.M., Zhang, R., and Wang, L.S. (2006) J. Phys. Chem. B, 110: 2141621418.

[57] Pinna, N., Grancharov, S., Beato, P., Bonville, P., Antonietti, M., and Niederberger, M. (2005) Chem. Mater., 17: 30443049 .

[58] Cölfen, H., Schnablegger, H., Fisher, A., Jentoft, J.C., Weinberg, G., and Schlogl, R. (2002) Langmuir, 18: 35003509.

[59] Svedberg, E.B., Ahner, J., Sukla, N., Ehrman, S.H., and Schilling, K. (2005) Nanotechnology, 16: 953956.

[60] Cölfen, H. and Pauck, T. (1997) Colloid Polym. Sci., 275: 175180.

[61] Svedberg, T. and Nichols, J.B. (1923) J. Am. Chem. Soc., 45: 29102917.

[62] Panine, P., Gradzielski, M., and Narayanan, T. (2003) Rev. Sci. Instrum., 74: 24512455. 
[63] Pedersen, J.S. (2002) In Neutrons, X rays and Light: Scatter ing Methods Applied to Soft Condensed Matter, edited by P. Lindner and T. Zemb; Amsterdam, the Netherlands: Elsevier; pp. 391420.

[64] Pedersen, J.S. (2004) J. Appl. Crystallogr., 37: 369380.

[65] Guinier, A. and Fournet, G. (1955) Small Angle Scattering of $X$ ray; New York: John Wiley.

[66] Pergushov, D.V., Remizova, E.V., Grazielski, M., Lindner, P., Feldthusen, J., Zezin, A.B., Müller, A.H.E., and Kabanov, V.A. (2004) Polymer, 45: 367 378.

[67] Burkhardt, M., Ruppel, M., Tea, S., Drechsler, M., Schweins, R., Pergushov, D.V., Gradzielski, M., Zezin, A.B., and Müller, A.H.E. (2008) Langmuir, 24: 17691777
[68] Ascencio, J.A., Perez, M., and Jose Yacaman, M. (2000) Surf. Sci., 447: 7380.

[69] Koga, K. and Sugawara, K. (2003) Surf. Sci., 529: 2335.

[70] Reyes Gasgaa, J., Tehuacanero Nuneza, S., Montejano Carrizalesb, J.M., Gaoc, X., and Jose Yacaman M. (2007) Top. Catal., 46: 2330.

[71] Wilcoxon, J.P., Martin, J.E., Parsapour, F., Wiedenman, B., and Kelley, D.F. (1998) J. Chem. Phys., 108: 91379143.

[72] Bigioni, T.P. and Whetten, R.L. (2000) J. Phys. Chem. B, 104: 69836986.

[73] Huang, T. and Murray, R.W. (2001) J. Phys. Chem. B, 105: 1249812502.

[74] Wang, G., Huang, T., Murray, R.W , Menard, L., and Nuzzo, R.G. (2005) J. Am. Chem. Soc., 127: 812813.

[75] Yang, Y. and Chen, S. (2003) Nano Lett., 3: 7579. 